Journal of Applied Pharmaceutical Science Vol. 6 (10), pp. 063-067, October, 2016

Available online at http://www.japsonline.com

DOI: $10.7324 / \mathrm{JAPS} .2016 .601008$

ISSN 2231-3354 (cc) BY-NC-sA

\title{
Bioanalytical Method Development and Validation for the Determination of Levocetirizine in Pharmaceutical Dosage Form and Human Plasma by RP-HPLC
}

\author{
Nilesh Jain ${ }^{1}$, Deepak Kumar Jain ${ }^{2 *}$, Ruchi Jain ${ }^{1}$, Vijay Kumar Patel ${ }^{2}$, Preeti Patel ${ }^{2}$, Surendra Kumar Jain ${ }^{1}$ \\ ${ }^{1}$ Sagar Institute of Research, Technology \& Science-Pharmacy, Ayodhya Bypass Road, Bhopal-462041, (MP) India. \\ ${ }^{2}$ Medicinal Chemistry Research Laboratory, SLT Institute of Pharmaceutical Sciences, Guru Ghasidas Central University, Bilaspur-495009, (CG) India.
}

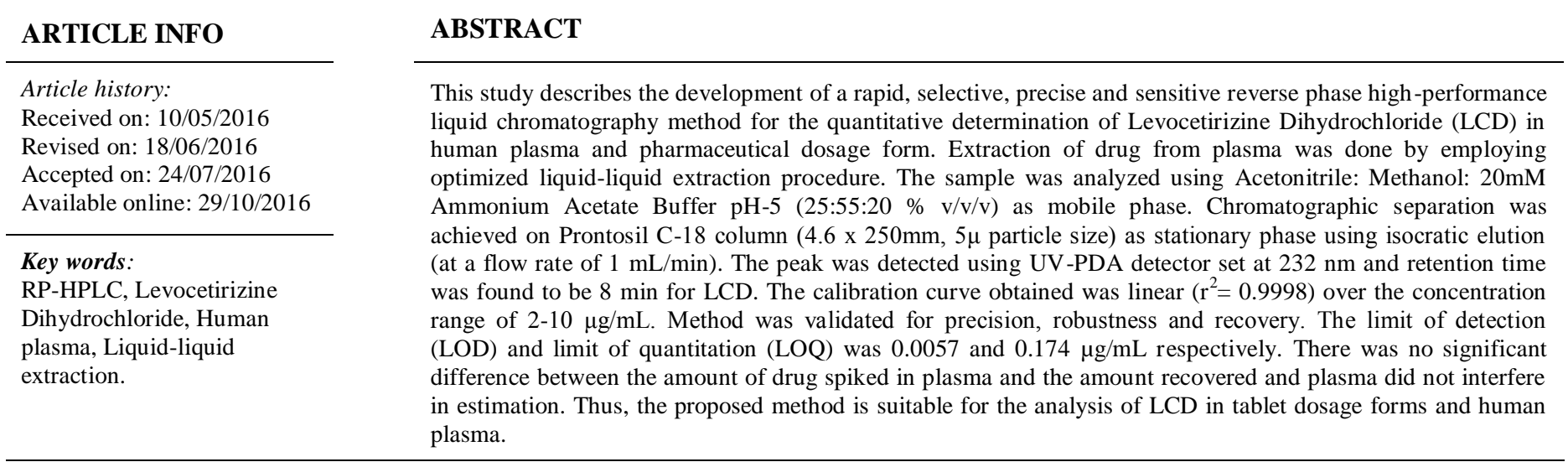

\section{INTRODUCTION}

Levocetirizine dihydrochloride (LCD), chemically is (2-[4-[(R)-(4-chlorophenyl) henylmethyl]-1-piperazinyl]ethoxy]acetic acid dihydrochloride) is a third generation non sedative antihistamine (Neil, 2001) and developed from the second generation antihistamine cetirizine. In many cases, the two racemic enantiomers differ in their pharmacokinetic and pharmacodynamic properties. Replacing existing racemates with single isomers has resulted in improved safety and/or efficacy profile of various racemates (Patel and Kothekar, 2006; Testa and Trager, 1990). It works by blocking histamine receptors and it is polar compound in nature.

* Corresponding Author

Deepak Kumar Jain, Medicinal Chemistry Research Laboratory, SLT Institute of Pharmaceutical Sciences, Guru Ghasidas Central University, Bilaspur-495009, (CG) India. Email: jaindeepak2022 @ gmail.com
LCD has the advantages of higher efficacy, less side effects and longer duration over other antihistamines and has begun to replace cetirizine in clinical therapy stepwise. It has been chemically proved that the half dosage form of LCD $(2.5 \mathrm{mg})$ has comparable antihistaminic activity to normal amount $(5.0 \mathrm{mg})$ of cetirizine in the treatment of allergic rhinitis and chronic idiopathic urticaria (Devalia et al., 2001; Grant et al., 2002).

LCD is official in Indian Pharmacopoeia (IP, 2007) and European Pharmacopoeia (EP, 2008) as well, in both the method describes for analysis of LCD is acid-base titration with $0.1 \mathrm{M}$ $\mathrm{NaOH}$ in acetone/water medium. Literature survey revealed that LCD has been reported to be determined by UV Spectrophotometry based on charge transfer reaction (Raghu and Basavaiah, 2012; Basavaiah et al., 2012), LC-MS-MS (Gunasakaran et al., 2010; Morita et al., 2008), RP-HPLC (Chaitanya Prasad et al., 2011) and by HPTLC (Bhusari and Dhaneshwar, 2010) in a variety of samples. 
LCD in combination with a number of other drugs in tablet dosage form has been assayed by UV- spectrophotometry (Prabhu et al., 2008; Merukar et al.,2009), ratio derivative spectrophotometry (Choudhari et al., 2010),TLC-densitometry (Smita et al., 2010; Khedkar et al.,2014), Stability indicating (Venkateswari et al., 2012) and RP-HPLC (Ashok Kumar et al., 2009; Ambadas and Vaishali, 2010; Kamarapu et al., 2010; Shaikh and Patil, 2010; Ishaq et al., 2015; Rao et al., 2015). However there is no method available for estimation of Levocetirizine in human plasma and pharmaceutical dosage form By RP-HPLC Therefore, an attempt was made to develop a new, rapid and sensitive method for the determination of LCD in human plasma. To access the reproducibility and wide applicability of the developed method, it was validated as per ICH norm, which is mandatory also (Code Q2A, 1994; Code Q2B, 1994).The chemical structures were represented in Figure 1.

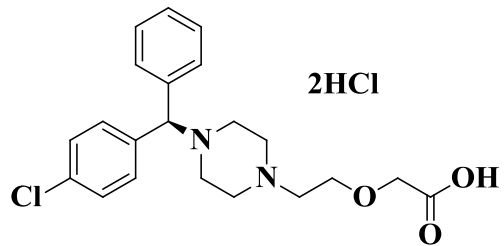

Fig. 1: Chemical structure of levocetirizine dihydrochloride.

\section{EXPERIMENTAL}

\section{Materials}

The pure drug sample of LCD $(99.56 \%)$ was obtained as gift sample from Reddy's Laboratory, Hyderabad. Milli-Q-water was used throughout the process, HPLC grade acetonitrile, methanol was purchased from Merck Ltd (Mumbai, India). All other chemicals and reagents used were of analytical grade only. The human plasma was received from Peoples Hospital, Bhopal, M.P., India. Liancet-L (5mg) Tablet was purchased from the local market.

\section{Equipments}

A high performance liquid chromatographic system from Young Lin 9100 comprising of manual injector, YL 9111 quaternary pump for constant flow and constant pressure delivery and Photodiode array detector (YL 9160 detector) connected to software YL clarity for controlling the instrumentation as well as processing the data generated was used.

\section{Chromatographic conditions}

The chromatographic analysis was performed by using a mobile phase of 20mM Ammonium Acetate Buffer (pH 5.0), Methanol and Acetonitrile (20:55:25 v/v). These were filtered through $0.45 \mu$ membrane filter and degassed by sonication before use.

The mobile phase was pumped isocratically at a flow rate of $1.0 \mathrm{~mL} / \mathrm{min}$ during analysis at ambient temperature. The run time was set at $10 \mathrm{~min}$ and the volume of injection was $20 \mu \mathrm{l}$ and eluent was detected at $232 \mathrm{~nm}$ on a Prontosil C-18 column (4.6 x $250 \mathrm{~mm}, 5 \mu$ particle size) Figure 2.

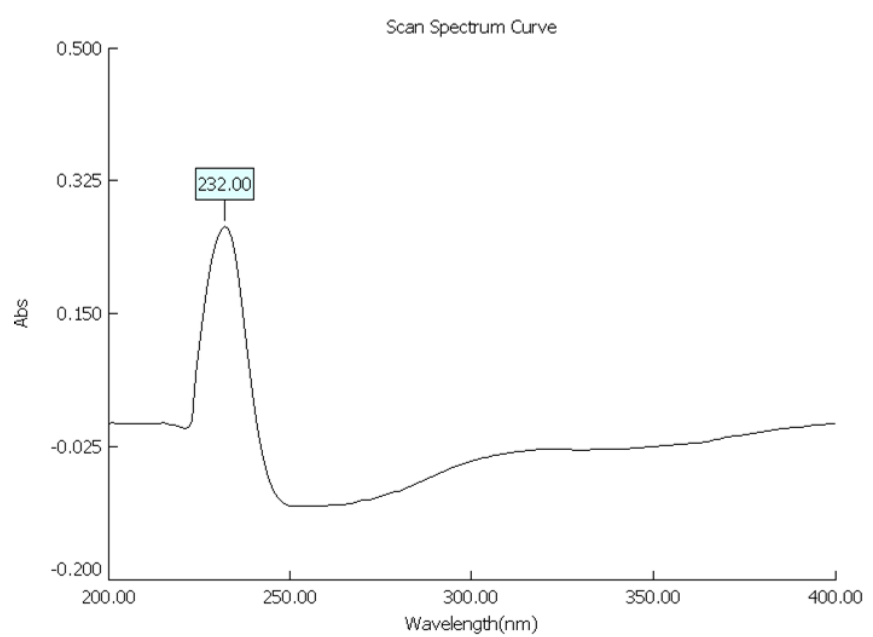

Fig. 2: UV spectra of LCD at $232.0 \mathrm{~nm}$.

\section{Selection of mobile phase}

Initially to estimate Levocetirizine number of mobile phase in different ratio were tried. Taking into consideration the system suitability parameter like RT, Tailing factor, No. of theoretical plates and HETP, the mobile phase found to be most suitable for analysis was Acetonitrile: Methanol: $20 \mathrm{mM}$ Ammonium acetate buffer ( $\mathrm{pH} 5.0$ ) in the ratio of 25:55:20 v/v/v. The mobile phase was filtered through $0.45 \mu$ filter paper to remove particulate matter and then degassed by sonication. Flow rate employed for analysis was $1.0 \mathrm{~mL} / \mathrm{min}$.

\section{Preparation of standard stock solution}

Accurately weigh and transfer 10mg of LCD of working standard into $50 \mathrm{~mL}$ clean dry volumetric flask add about $40 \mathrm{~mL}$ of diluents (Mobile Phase) and sonicate to dissolve it completely and make volume up to the mark with same solvent (Stock Solution). Further pipette $5 \mathrm{~mL}$ of above stock solution in to a $10 \mathrm{~mL}$ volumetric flask and dilute up to the mark with diluents. Further pipette 0.2 to $1.0 \mathrm{~mL}$ of above stock solution into a $10 \mathrm{~mL}$ volumetric flask and dilute up to the mark with diluents. This gives the solutions of $2-10 \mu \mathrm{g} / \mathrm{mL}$ for drug.

\section{Preparation of blank plasma}

To $1 \mathrm{~mL}$ of plasma, $4 \mathrm{~mL}$ of Acetonitrile was added; the solution was mixed thoroughly and left to stand for $5 \mathrm{~min}$ at room temperature. After $5 \mathrm{~min}$ the solution was centrifuged at 10000 $\mathrm{rpm}$ for $12 \mathrm{~min}$ at $4^{\circ} \mathrm{C}$. The clear supernatant liquid was removed, filtered through $0.22 \mu$ syringe filter and injected directly into HPLC system.

\section{Preparation of standard plasma stock solution}

To prepare calibration standards and quality control samples, appropriate quantities of the various diluted standard solutions added to blank plasma to obtain drugs in the 
concentrations range of $2-10 \mu \mathrm{g} / \mathrm{mL}$ for LCD. These were stored at $-20^{\circ} \mathrm{C}$ and $20 \mu \mathrm{L}$ volume of each sample was injected and chromatographed.

\section{Assay in formulations}

To determine the content of the drug in the formulations, twenty marketed tablets of Liancet-L (Azillian Healthcare Pvt. Ltd., Ahmedabad) were weighed and ground to a fine powder; amount equal to $5 \mathrm{mg}$ of LCD was taken in $50-\mathrm{mL}$ volumetric flask before $50 \mathrm{~mL}$ diluents was added.

The content of the flask was shaken for about $60 \mathrm{~min}$. This solution was filtered through Whatman filter paper to separate out the insoluble excipients, and further dilutions were carried out to obtain the desired concentration. Final solutions were filtered through a $0.45-\mu \mathrm{m}$ Millipore filter before injection into the HPLC.

\section{RESULT AND DISCUSSION}

\section{Method validation}

The method was validated according to $\mathrm{ICH}$ guidelines for validation of analytical procedures. The method was validated for the parameters like linearity, precision, specificity, limit of detection (LOD), limit of quantitation (LOQ), accuracy and robustness. The linearity of this method was proved using linear correlation of the peak-area values and appropriate concentrations.

\section{Linearity, limit of detection and quantification}

Under the previously described experimental conditions, linear correlation between the peak area and applied concentration was found in the concentration range $2-10 \mu \mathrm{g} / \mathrm{mL}$. The regression statistics are shown in Table 1.

Table 1: Regression statistics and LOD and LOQ.

\begin{tabular}{ccccc}
\hline Drug & $\begin{array}{c}\text { Regression } \\
\text { equation }\end{array}$ & $* \mathbf{R}^{2}$ & $\begin{array}{c}* \mathbf{L O D} \\
(\boldsymbol{\mu g} / \mathbf{m L})\end{array}$ & $\begin{array}{c}* \mathbf{L O Q} \\
(\boldsymbol{\mu g} / \mathbf{m L})\end{array}$ \\
\hline Levocetirizine & $\mathrm{y}=396.6 \mathrm{x}+24.80$ & 0.999 & 0.0057 & 0.174 \\
\hline
\end{tabular}

*Average of five determination

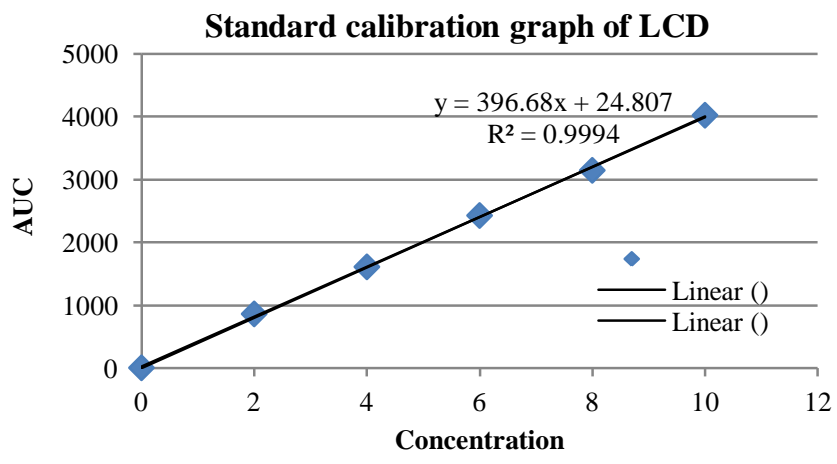

Fig. 3: Standard calibration graph of LCD.
The LOD and LOQ at concentrations where the signalto-noise ratios were equal to 3 and 10 respectively were determined to be $0.0057 \mu \mathrm{g} / \mathrm{mL}$ and $0.174 \mu \mathrm{g} / \mathrm{mL}$ for levocetirizine dihydrochloride respectively. The correlation coefficient of this dependence was calculated to be 0.999 for levocetirizine dihydrochloride Figure 3.

\section{Precision and Robustness}

Precision of the methods was studied at three levels as at repeatability, intermediate precision (Day to Day and analyst to analyst) and reproducibility in synthetic samples using placebo mixtures. Mean \pm SD and $\%$ relative standard deviation (RSD) values were used to express precision. As per ICH norms, small, but deliberate variations in concentration of the mobile phase were made to check the method's capacity to remain unaffected. The ratio of mobile phase was change from, ACN: Methanol: Ammonium Acetate Buffer pH- 5 (25:55:20 \% V/V/V), to $(25: 54: 21 \% \mathrm{~V} / \mathrm{V} / \mathrm{V})$.Results of precision and robustness are reported in Table 2.

Table 2: Result of precision and robustness

\begin{tabular}{lcc}
\hline \multicolumn{1}{c}{ Validation Parameter } & $\begin{array}{c}\text { Percentage } \\
\text { Mean } \pm \text { S.D*. }(\mathbf{n}=\mathbf{1 5})\end{array}$ & $\begin{array}{c}\text { Percentage } \\
\text { RSD }^{*}\end{array}$ \\
\hline Repeatability & $99.23 \pm 0.09$ & 0.097 \\
Reproducibility & $97.40 \pm 0.07$ & 0.078 \\
Intermediate precision & $97.24 \pm 0.17$ & \\
Day to Day & $97.11 \pm 0.13$ & 0.179 \\
Analyst to Analyst & $96.87 \pm 0.10$ & 0.144 \\
Robustness* & Mean of fifteen determinations (3 replicates at 5 concentration level)
\end{tabular}

\section{Accuracy}

The accuracy of the proposed methods was assessed by recovery studies at three different levels i.e. $80 \%, 100 \%$ and $120 \%$. The recovery studies were carried out by adding a definite concentration of standard drug $(80 \%, 100 \%$, and $120 \%$ ) to preanalyzed sample solutions. The resulting solutions were then re-analyzed by proposed methods. The value of mean recoveries was found to be in ranging from 97.76 to 99.883 for LCD. Total amount of drug found and percentage recovery was calculated. Result of recovery studies are reported in Table 3.

Table 3: Results from recovery studies of levocetirizine.

\begin{tabular}{ccc}
\hline \multirow{2}{*}{ Recovery Level \% } & Levocetirizine \\
\cline { 2 - 3 } & \% MEAN \pm SD & \\
\hline $\mathbf{8 0}$ & $99.88 \pm 0.106$ & \% RSD* \\
$\mathbf{1 0 0}$ & $97.76 \pm 1.317$ & 0.106 \\
$\mathbf{1 2 0}$ & $99.35 \pm 0.160$ & 0.161 \\
\hline
\end{tabular}

*Average of five determination.

Specificity

A representative chromatogram (Figure 4) was generated to show that other components, which could be present in the sample matrix, are resolved from the parent analyte. No significant changes in retention times of the drugs in the presence and the absence of excipients clearly indicated the specificity of the method. 

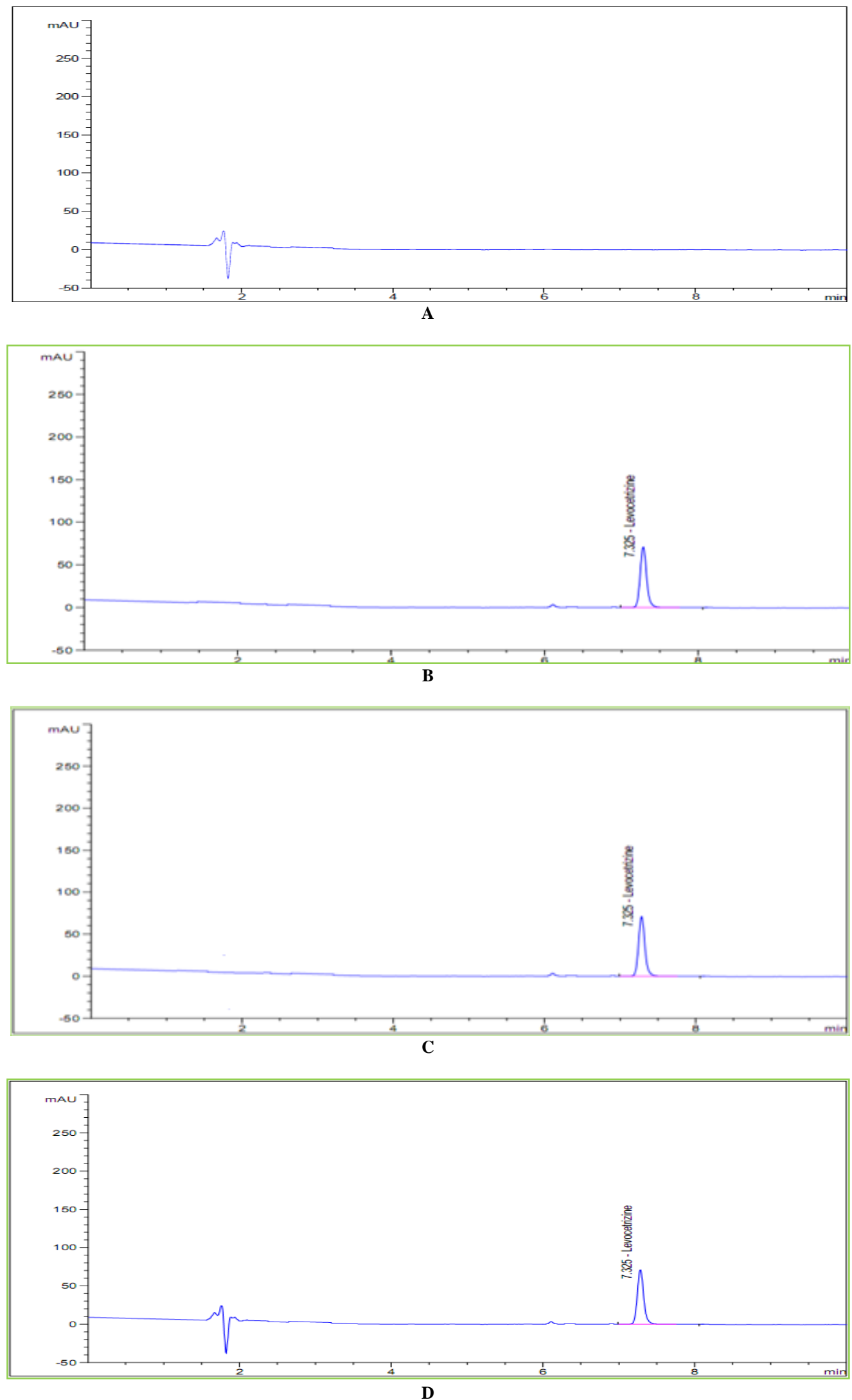

Fig. 4: Representative chromatogram of blank plasma (A) and representative chromatogram of levocetirizine pure drug (B), representative chromatogram of levocetirizine in formulation (c), in human plasma (d). 


\section{Application in human Plasma}

It was observed after spiking the analyte in the plasma sample that there was no significant difference between the amount of drug spiked in plasma and the amount recovered. The recovery values (Table 4) in human plasma clearly indicate the applicability of the present method for the required purpose (Figure 4).

Table 4: Accuracy and precision in human plasma

\begin{tabular}{cccc}
\hline Analyte & $\begin{array}{c}\text { Spiked } \\
\text { conc. }(\boldsymbol{\mu g} / \mathbf{m L})\end{array}$ & $\begin{array}{c}\text { Precision } \\
(\boldsymbol{\%} \text { RSD })\end{array}$ & $\begin{array}{c}\text { Accuracy } \\
(\boldsymbol{\%})\end{array}$ \\
\hline Levocetirizine & $\mathbf{2}$ & 0.92 & 99.60 \\
& $\mathbf{4}$ & 1.02 & 98.56 \\
& $\mathbf{6}$ & 1.50 & 98.45 \\
\hline
\end{tabular}

*Average of five determination.

\section{CONCLUSION}

Based on all the results obtained by HPLC studies, it was concluded that the present method was fast and easy to perform. The linearity range, precision, accuracy, Robustness, LOD, LOQ and specificity were processed to establish the suitability of the method and the confirmed results were obtained. HPLC has several superiorities compared with UV spectrophotometry, such as smaller detection and quantification limits, small sample volumes and specificity. Thus, the developed HPLC method is rapid, reliable, cost-effective and can be proposed for routine analysis laboratories and quality control purposes and are very beneficial for pharmaceutical companies, clinicians and physicians and also can be beneficial for the studies of drug interaction with other combinations.

Financial support and sponsorship: Nil.

Conflict of Interests: There are no conflicts of interest.

\section{REFERENCES}

Neil JO. 2001. The Merck Index. 13th ed. Merck Research Laboratories, Merck and Co. Inc., Maryndale, White House Station, New Jersey.

Patil PA, Kothekar MA. Development of safer molecules through chirality. Indian J Med Sci, 2006; 60(10): 427-437.

Testa B, Trager WF. Racemates versus enantiomers in drug development: Dogmatism or pragmatism. Chirality, 1990; 2(3):129-133.

Devalia JL, Hanotte F, Baltes E, Vos CD. A randomized, doubleblind, crossover comparison among cetirizine, levocetirizine and ucb 28557 on histamine-induced cutaneous responses in healthy adult volunteers. Allergy, 2001; 56(1):50-57.

Grant JA, Riethuisen JM, Moulaert B, Vos CD, A double-blind, randomized, single-dose, crossover comparison of levocetirizine with ebastine, fexofenadine, loratadine, mizolastine, and placebo: suppression of histamineinduced wheal-and-flare response during 24 hours in healthy male subjects. Ann Allergy Asthma Immunol, 2002; 88(2): 190-197.

Indian Pharmacopoeia, Vol. II, The controller of Publications, Ministry of Health and Family Welfare: Govt. of India, New Delhi: 2007; p 1290.

European Pharmacopoeia, 6.0, Vol. II, EDQM, Council of Europe: Stranbourg, France: 2008; p 1479.

Raghu MS, Basavaiah K. Optimized and validated spectrophotometric methods for the determination of levocetirizine in pharmaceuticals based on charge transfer reaction. J Asso Arab Uni Basic Appl Sci, 2012; 12:33-41

Basavaiah K, Raghu MS, Vinay KB. Simple and rapid spectrophotometric assay of levocetirizine in pharmaceuticals through charge- transfer complexation using chloranilic acid and 2,3-dichloro-5,6dicyanoquinone as $\pi$-acceptors. Bull Chem Soc Ethiop, 2012; 26(3):319-328.

Gunasakaran S, Rao N, Arunkumar R, Olaganathan A. Determination of levocetirizine in human plasma by liquid chromatography electrospray tandem mass spectrometry. Biomirror, 2010; 1(3):12-27.

Morita MR, Berton D, Boldin R, Barros FAP, Meurer EC, Amarante AR, et al. Determination of levocetirizine in human plasma by liquid chromatography-electrospray tandem mass spectrometry: Application to a bioequivalence study. J Chromatogr B, 2008; 862:132-139.

Chaitanya Prasad MK, Vidyasagar G, Sambasiva Rao KRS, Induri M, Ramanjeneyulu S. Development of validated liquid chromatographic method for estimation of levocetirizine from pharmaceutical dosage forms. J App Pharma Sci, 2011; 01(10): 95-97.

Bhusari VK, Dhaneshwar SR. Application of a stability-indicating TLC method for the quantitative determination of Levocetirizine in pharmaceutical dosage forms. Int J Adv Pharma Sci, 2010; 1:387-394.

Prabhu SL, Shirwaikar AA, Shirwaikar A, Kumar CD, Kumar GA. Simultaneous UV spectrophotometric estimation of ambroxol hydrochloride and levocetirizine dihydrochloride. Indian J Pharm Sci, 2008; 70(2):236-238.

Merukar SS, Mhaskar PS, Bavaskar SR, Burade KB, Dhabale PN. Simultaneous spectrophotometric methods for estimation of levocetirizine and pseudoephedrine in pharmaceutical tablet dosage form. J Pharm Sci Res, 2009; 1(2):38-42.

Choudhari V, Kale A, Abnawe S, Kuchekar B, Gawli V, Patil N. Simultaneous determination of montelukast sodium and levocetirizine dihydrochloride in pharmaceutical preparations by ratio derivative spectroscopy. Int J Pharm Tech Res, 2010; 2(1): 4-9.

Smita S, Sharma MC, Kohli DV, Sharma AD. Development and validation of TLC-densitometry method for simultaneous quantification of montelukast sodium and levocetirizine dihydrochloride pharmaceutical solid dosage form. Der Pharm Lettre, 2010; 2(1): 489-494.

Khedkar AN, Veer SU, Rakh MS, Rao JR. Simultaneous estimation and validation of levocetirizine, pseudoephedrine and ambroxol in bulk and combined tablet dosage form by HPTLC. Int J Pharma Qua Assur, 2014; 6(1); 24-31.

Venkateswari P, Kumar GVS, Puranik SB, Srinivas S, Reddy R, Ramya G, et al. Development of stability indicating rp-hplc method for the simultaneous estimation of ambroxol hydrochloride and levocetirizine dihydrochloride. Int J Adv Pharma Anal, 2012; 2(2): 34-40.

Ashok Kumar S, Senthil Raja M, Perumal P. RP-HPLC method development and validation for simultaneous estimation of montelukast sodium and levocetirizine dihydrochloride. Int J Pharm Res, 2009; 1: 8-12.

Ambadas RR, Vaishali SN. Determination of montelukast sodium and levocetirizine dihydrochloride in combined pharmaceutical dosage form by RP-HPLC. Lat Am J Pharm, 2010; 29(6):1020-1023.

Kamarapu SK, Vaijayanthi, Bahlul ZEA, Venisetty RK. Development of rp-hplc method for the analysis of levocetirizine dihydrochloride and ambroxolhydrochloride in combination and its application. Int J Pharm Sci Nanotech, 2010;3(1): 893-897.

Shaikh KA, Patil AT. A stability-indicating LC method for the simultaneous determination of levocetirizine dihydrochloride and pseudoephedrine sulfate in tablet dosage forms. Int J Chem Tech Res, 2010; 2(1): 454-461.

Ishaq BM, Prakash KV, Mohan GK, Muneer S, Ahad HA. RPHPLC method for simultaneous estimation of levocetirizine dihydrochloride and montelukast sodium in tablets. Indian E-J Pharma Sci, 2015; 01(01):18-20.

Rao AS, Pavankumar KLNNSVK, Satyanarayana P, Sastrya GS. Validated reverse phase hplc method for the simultaneous estimation of guaifenesin, ambroxol and levocetirizine in pharmaceutical dosage forms. W J Pharm Pharma Sci, 2015; 4(9): 1735-1747.

Code Q2A-Text on Validation of Analytical Procedure Step-3 Consensus Guideline, 1994, ICH Harmonised Tripartite Guideline.

Code Q2B- Validation of Analytical Procedure Methodology Step-4 Consensus Guideline, 1994, ICH Harmonised Tripartite Guideline.

\section{How to cite this article:}

Jain N, Jain DK, Jain R, Patel VK, Patel P, Jain SK. Bioanalytical Method Development and Validation for the Determination of Levocetirizine in Pharmaceutical Dosage Form and Human Plasma by RP-HPLC. J App Pharm Sci, 2016; 6 (10): 063-067. 